\title{
Moving towards Evidence-informed Policy Development on Third Party Accreditation of Healthcare Facilities in Light of the Universal Health Care Act: Policy Analysis
}

\author{
Michael Antonio F. Mendoza, DDM, MA, ${ }^{1,2}$ Ma-Ann M. Zarsuelo, RND, MSc, ${ }^{1,3}$ \\ Gabriel R. Borlongan, MD, MPM, ${ }^{1}$ Ma. Esmeralda C. Silva, MPAf, MSPPM, PhD, ${ }^{1,4}$ \\ Hilton Y. Lam, MHA, PhD ${ }^{1,3}$ and Carmencita D. Padilla, MD, MAHPS ${ }^{5}$ \\ ${ }^{1}$ University of the Philippines Manila Health Policy Development Hub \\ ${ }^{2}$ College of Dentistry, University of the Philippines Manila \\ ${ }^{3}$ Institute of Health Policy and Development Studies, National Institutes of Health, University of the Philippines Manila \\ ${ }^{4}$ College of Public Health, University of the Philippines Manila \\ ${ }^{5}$ University of the Philippines Manila
}

\begin{abstract}
Background. The Universal Health Care (UHC) Act seeks to delineate the roles of key agencies and stakeholders towards equity in access to quality and affordable health care. Under the pillar of health regulation, the Philippine Health Insurance Corporation is mandated to recognize third party accreditation mechanisms as a basis for granting incentives to health facilities that provide better service quality, efficiency, and equity.

Methods. A systematic review of literature was conducted to generate a policy brief that outlined the strengths and weaknesses of the current accreditation system, and how to address arising fragmentation issues in implementation based on international and local evidence. To generate recommendations from a multi-stakeholder approach, a roundtable discussion enjoined by all major stakeholders of the policy issue was conducted by the University of the Philippines Manila Health Policy Development Hub in collaboration with the Department of Health. Thematic analysis of the RTD and the literature review were utilized in crafting the position statement with the general aim of producing consensus policy recommendations, as inputs in the Implementing Rules and Regulations of the Act.
\end{abstract}

Results. Policy analysis using results of literature review and policy discussion was crafted, with thematically arranged recommendations in the domains of leadership and governance, financing and sustainability, standards development, program development, and continuing quality improvement that could help the national health system in determining third party accreditation mechanisms set forth by the UHC Act. Significant issues raised was the composition and requirements of the third party accreditor and the risks in transition.

Conclusion and Recommendation. With the PhilHealth Benchbook setting the standards and with the expressed commitment of stakeholders for third party accreditation, it is an opportune time for the UHC Act to institutionalize the accreditation mechanisms that will address existing challenges of PhilHealth accreditation. The literature review and discussion bring forth the proposed tool for the criteria in selecting third party accreditors.

Key Words: Accreditation, National Health Insurance, Universal Health Care, Health Regulation

\section{INTRODUCTION}

Corresponding author: Ma-Ann M. Zarsuelo, RND, MSc

UP Manila Health Policy Development Hub

National Institutes of Health

University of the Philippines Manila

623 Pedro Gil St., Ermita, Manila 1000, Philippines

Email: mmzarsuelo@up.edu.ph
Delivering quality health care services is one of the three main goals of health systems. ${ }^{1}$ Nevertheless, quality, access, and cost are inter-related factors of healthcare where it is impossible to improve on one without impacting the other two. For example, inequitable access to health while containing costs may result in poorer quality of care. Likewise, 
improving quality of care across all points of services may translate to higher health expenditures. ${ }^{2}$ Improving all three goals is complex and a delicate balance that considers the values prioritized by the populations being served is needed. ${ }^{3}$ The Philippine government formally institutionalized these goals through the enactment of the Republic Act 11223 or known as the Universal Health Care (UHC) Act of 2019. Part of the changes sought in the regulation of health facilities is the recognition of third party accreditation mechanisms, which would enable facilities to be contracted by the Philippine Health Insurance Corporation, or PhilHealth, the national government agency in charge of the National Health Insurance Program.

To ascertain evidence-informed policy development of the Implementing Rules and Regulations of the UHC Act, the Department of Health (DOH), the lead implementing agency of the Act, collaborated with the University of the Philippines Manila Health Policy Development Hub (UPM $\mathrm{HPDH}$ ) as the research team, to conduct research and a series of UHC roundtable discussion engaging all major key stakeholders of the selected policy issues, one of which is third party accreditation.

To provide a framework for the discussion, the research team conducted pre-work through a systematic review of literature. For the policy issue of interest, it focused on the common themes that emanated from health facility accreditation with health insurance programs, and a brief local history of health facility accreditation. This roundtable discussion aimed to frame the strategies in identifying the criteria and mechanisms of the third party accreditor, taking into account the strengths and weaknesses of the current system and how to address arising fragmentation issues in the implementation. From these, strategic reforms in health facilities regulation were discussed with the following discussion questions:

1. What is the impact of PhilHealth accreditation, particularly on the quality, market, and accountability?

2. What are the good practices of international and local licensing and accreditation?

3. What are the proposed criteria for identifying third party accreditors and their mechanisms?

4. What are the risks and mitigating measures in transitioning from PHIC to an outsourced third party?

As the UHC Act delves on the broad realm of regulation, including assurance on the safety and quality of medicines and other health technologies, and the exploration of the potential of accreditation of networks of facilities, it is not included as main concerns of this study.

\section{METHODS}

\section{Pre-work Research}

A systematic review of literature was conducted to serve as input for the policy brief that sets the discussion points in the policy roundtable discussion among identified relevant stakeholders. Elements of experiences in accreditation at the national level in the Philippines or similar settings were sought. Figure 1 shows the PRISMA diagram of the article search. To initiate the scoping, a search through the PUBMED library was conducted in January 2019 using the $\mathrm{MeSH}$ terms "hospital" and "accreditation" and the MeSH terms "health" and "accreditation." With duplicates excluded, the combination of both searches resulted in 3,230 articles. To ensure that evidence was updated and applicable in the review and discussion, only records published between 2014 January 1 and 2019 January 31, were included. Records deemed as clinical studies by the search engine, which were not the focus, were filtered out. Among the 369 records, titles were screened for relevance with 340 articles excluded if these focus on the effect of accreditation to individual or population outcomes; specific set or itemized standards; perspectives on facility management as a journey of a facility towards accreditation; and accreditation of educational or training programs, specific specialties, departments within the hospital, or to public health functions. In total, 27 full-text articles were examined to identify if there are pertinent narrative elements and qualitative information. The unavailability of the full-text versions in English of six articles and the ineligibility of 20 of the remaining articles, resulted in checking of references of the available articles, monographs on health care management, and a search on Google with the keywords initially used. This yielded 15 additional records.

\section{Review of literature}

The following findings of the literature review served as inputs in crafting the policy brief with proposed delineation of roles and organogram of third party accreditation of health facilities.

\section{External Quality Assessment}

In assessing quality in health care, external quality assessment is commonly practiced. Accreditation or the systemic assessment of the healthcare facility in comparison with standards is the most frequent type. ${ }^{4}$ It aims to encourage the development of the organization under study, as conducted by professional peer reviewers and administered by an independent body. It distinguishes itself from licensing, which is mandatorily performed by the government to all facilities which wish to operate and set minimum standards for assuring the safety of the utilized services. ${ }^{5}$ Evidence showed that the effectiveness of accreditation mostly focuses on parameters on acute care, linking to organizational impacts and relationship to quality measures. The improvement in the performance of accredited facilities is more pronounced in the long run or during higher levels of accreditation (incomplete comparison). It is also associated with stronger organizational leadership, a more amicable organizational culture; integration of continuing quality improvement in daily processes; and standardization 


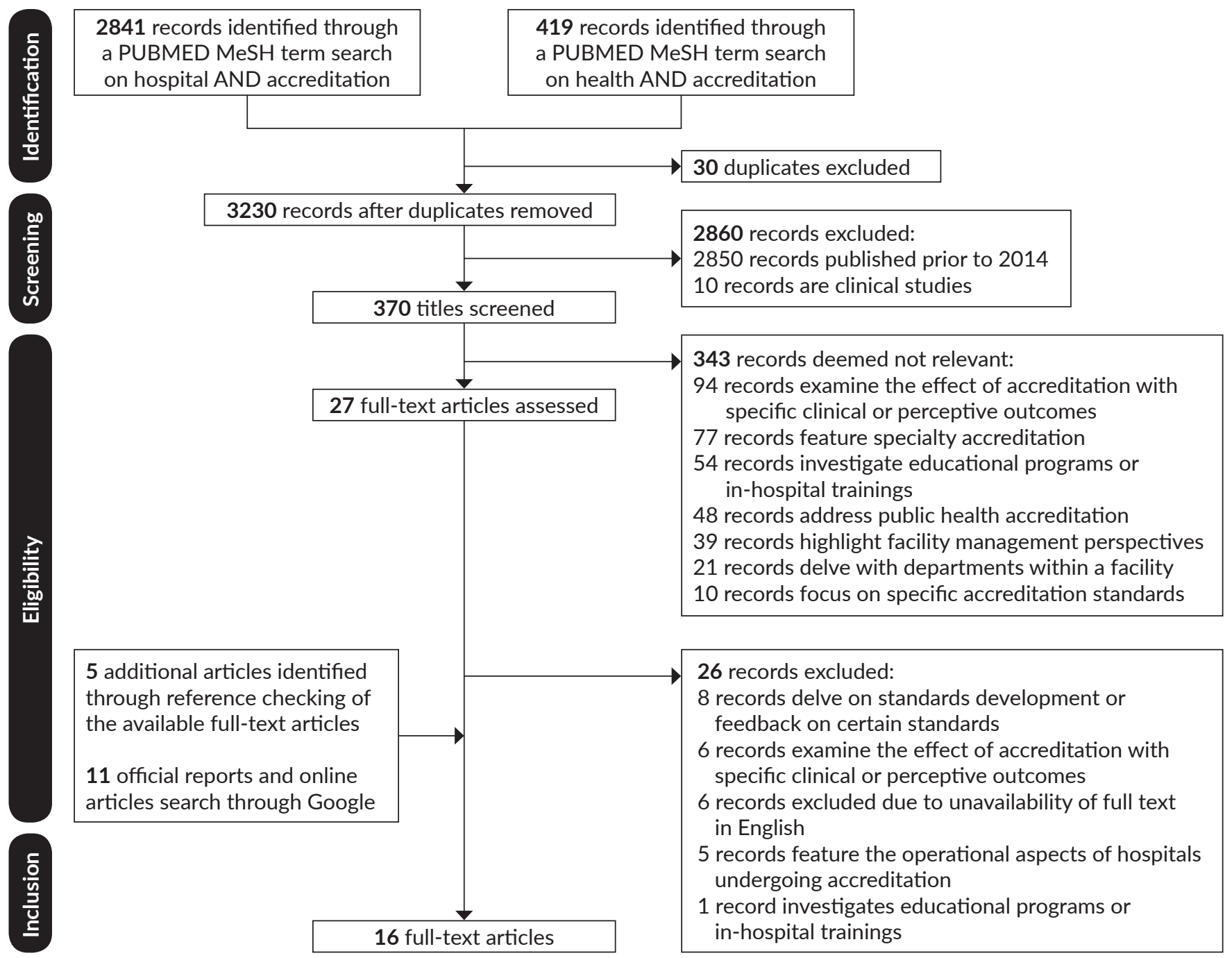

Figure 1. PRISMA diagram of identified records included in the review.

of care practices. In the management domain, feedback, and accountability mechanisms are well established within the hospitals and among individual providers, eventually leading to higher personnel satisfaction, imbibing a positive attitude on these processes. ${ }^{6}$

The program and organizational factors influencing the implementation of accreditation systems have been classified by Zafrifaftar and Aryankhesal (2016) into three levels. The first level is the legal support for regulatory initiatives from the government. ${ }^{7}$ The second level focuses on the supportive drivers for the hospitals to pursue accreditation. ${ }^{7}$ These drivers would lead to financial sustainability for the agency, while also improving profit, promoting efficiency, or minimizing expenditures of hospitals. ${ }^{7}$ Accreditation systems are costly and thus must ensure that financial incentives for the hospitals are delivered, either through governmental support or insurance agencies. Another approach is to market accreditation to the end-beneficiaries. ${ }^{7}$ When patients consider the quality of care as a premium and criteria in choosing health providers, this will drive productive competition among the service providers. The third level is the professional requirement wherein the activity implementation should be of the best quality. Standards set should be acceptable to the professionals' understudy, as relevant to a national or local context, and assessed under reliable survey practices, specifically by trained, competent assessors. ${ }^{7}$

In the Universal Health Care Act, the policy landscape of accreditation will shift. Section 27 (Safety and Quality) states that "PhilHealth shall establish a rating system under an incentive scheme to acknowledge and reward health facilities that provide better service quality, efficiency, and equity: provided, that PhilHealth shall recognize third party accreditation mechanisms and may use these as the basis for granting incentives." While this section does not outrightly specify that PhilHealth divests itself of its accrediting function, it provides room for an outsourced body involved solely on accreditation as separate from PhilHealth's purchasing function. ${ }^{8}$ 


\section{Existing Policies on Accreditation}

The Department of Health licensed 1,255 or $85.6 \%$ of the 1,465 private and government hospitals as of April 30, 2019, wherein PhilHealth accredits 1,250 of these for basic participation. ${ }^{9,10}$ The Hospital Licensure Act of 1965 formally introduced licensing as a function of the government through the Bureau of Medical Services, a precursor of the current Department of Health (DOH). The scope is mostly on compliance with other national laws, physical, and architectural requirements. The National Health Insurance Act (NHIA) of 1995 introduced accreditation as a regulatory mechanism through PhilHealth. In 2001, PhilHealth released its first Benchbook on Quality Assurance, introducing process and outcome-focused standards. After that, each agency set up different standards for licensing and accreditation that sometimes overlap and creates confusion among health care providers and institutions. ${ }^{11}$

Since 2013, the revised implementing rules and regulations (IRR) of the NHIA identified PhilHealth as the agency that has the mandate to prescribe standards and implement the process of accreditation and quality assurance for healthcare providers and healthcare institutions. With the revision of the NHIA and its IRR in 2013, the participation of healthcare institutions is through two levels, upon compliance with rules and processes: basic and advanced. At the minimum, a hospital must be licensed by DOH, operating for at least three years and commits to performance, as evidenced by an internal continuing quality assurance program conforming with the standards set by PhilHealth. Compliance makes them eligible for Basic Participation after passing the accreditation survey. A second higher level of Advanced Participation, or Center of Excellence, is awarded to hospitals that are already engaged for Basic Participation and can pass another set of standards that includes structural and process indicators. Outcome indicators such as hospital infection rates, are also assessed but usually hampered by poor data availability in the hospitals. ${ }^{12}$

Further administrative issuances reconcile the differences in the scope of standards between the Department of Health (hospital licensing) and PhilHealth (hospital accreditation for the National Health Insurance Program or NHIP). Streamlining of licensing and accreditation solved issues in accreditation gaps or the time asynchrony of both processes to maximize operations. PhilHealth has been reported to be stringent on accreditation policies to hospitals ${ }^{13}$ that as of 2015, just one-third of all licensed hospitals by DOH remains to be accredited. ${ }^{10}$ This limits access to health services even if the General Appropriations Act of 2012 provides a more accommodating policy in terms of accreditation. ${ }^{12}$

Monitoring the performance of hospitals in terms of quality was found to be hindered by the lack of PhilHealth workforce. Erring providers, in terms of the quality of services, were rarely de-accredited. Only sampled hospitals, and those suspected of fraud underwent these assessments. ${ }^{13}$ While these can be rendered more efficient in part by information and communication technology solutions, fragmented systems and poor connectivity cripple the ability of PhilHealth to ensure timely payment according to good performance. ${ }^{14}$

At present, accreditation of health care providers and health institutions in the Philippines is voluntary and linked to financial incentives from the NHIP. This is currently governed by PhilHealth - the largest purchaser of healthcare services. Various private and non-government entities have been working with hospitals in the Philippines. Aside from PhilHealth, the Philippine Tripartite Accreditation for Health Facilities (PTAHF), Inc., an independent, non-profit organization composed of three organizations of hospital and nursing service administrators, assist hospitals to guide them in complying with the PhilHealth standards for accreditation. ${ }^{15}$ Though it assesses hospitals, PTAHF is not the party responsible for PhilHealth accreditation. ${ }^{15}$ In 1996, the Philippine Society for Quality in Healthcare Inc. (PSQua) was established in coordination with $\mathrm{DOH}$ to promote quality in healthcare services with an emphasis on assurance, improvement, and management by providing conceptual framework and process, standard-setting and monitoring; and capacity-building for quality assurance. ${ }^{16}$ Apart from these, other sought-after accreditations are from the Joint Commission International, National Accreditation Board for Hospitals, Philippine Quality Awards, International Organization for Standardization, and Investors in People. International accreditation is a prospect by large private hospitals to leverage with international collaborators and a flag for medical tourism. ${ }^{17}$

Section 60 of the NHIA IRR of 2013 states that PhilHealth shall "develop a policy through the Hospital Accreditation Commission (HAC) for implementation of third party accreditation." In early 2010, the third party accreditor has already been envisioned to be a national accreditation body separate from $\mathrm{DOH}$ and PhilHealth. Based on the PhilHealth Benchbook standards, the Philippine Council for Accreditation of Health Organizations (PCAHO), a non-governmental organization, was recommended to serve this role in $2011 .{ }^{19}$ Historically, PCAHO has been designated as the authorized Quality Certifying Body for Quality Standard System in accrediting clinics and hospitals for overseas Filipino workers. ${ }^{18}$ PCAHO was registered as a non-stock and non-profit private organization in the Securities and Exchange Commission in 1999. ${ }^{20}$ However, as a non-government organization, which by law cannot receive government funds, it is now prevented from charging accreditation fees, or being granted a subsidy by either DOH or PhilHealth, not unless it opts to submit a proposal for additional funding from $\mathrm{DOH}$, PhilHealth or other donor agencies. ${ }^{19,20,21}$ Because of this limitation, it was then recommended that an independent body composed of government agencies and major health professional societies be formed to fulfill the role of surveying hospitals according to the PhilHealth standards. This body was institutionalized 
Table 1. Gaps and challenges of PhilHealth-led accreditation system and recommendations in setting up and running an ideal accreditation system within the Philippine context under the UHC Act

\begin{tabular}{|c|c|c|}
\hline Domains $^{9,10}$ & $\begin{array}{l}\text { Gaps and challenges in the current } \\
\text { set-up with PHIC as accreditor }{ }^{11,13,14}\end{array}$ & $\begin{array}{l}\text { Recommendations to achieve an ideal Philippine } \\
\text { accreditation agency under UHC Act }{ }^{11,13}\end{array}$ \\
\hline $\begin{array}{l}\text { Leadership and } \\
\text { Governance }\end{array}$ & $\begin{array}{l}\text { - NHIA of } 2013 \text { not prescriptive } \\
\text { in the transfer of function or role } \\
\text { on accreditation } \\
\text { - Hospital Accreditation Committee } \\
\text { limited in composition } \\
\text { - Ratings on accreditation not } \\
\text { publicly disseminated }\end{array}$ & $\begin{array}{l}\text { - Executive Order from the Office of the President and/or joint administrative } \\
\text { order from DOH and PhilHealth for the recognition of a third party accreditor, } \\
\text { with possible funding for the first three years until all hospitals are surveyed } \\
\text { - Stakeholder mapping and involvement at the executive level or decision- } \\
\text { making panel } \\
\text { - Public dissemination of results of accreditation survey online and with local } \\
\text { chief executives }\end{array}$ \\
\hline $\begin{array}{l}\text { Financing and } \\
\text { Sustainability }\end{array}$ & $\begin{array}{l}\text { - Recurrent issues on the delay of } \\
\text { claims reimbursement } \\
\text { - Non-interoperability of electronic } \\
\text { information systems limits their } \\
\text { use for financial management }{ }^{14}\end{array}$ & $\begin{array}{l}\text { - Shorter turn-around time (under } 28 \text { working days) }{ }^{14} \\
\text { - Collaboration with DOH, PHIC, and Department of Information and } \\
\text { Communications Technology (DICT) on the establishment of health } \\
\text { infostructure standards to ensure interoperability of systems and health info } \\
\text { standards }^{14}\end{array}$ \\
\hline $\begin{array}{l}\text { Standards } \\
\text { Development }\end{array}$ & - Benchbook of Standards ${ }^{14}$ & $\begin{array}{l}\text { - Inclusion of specific and } \mathrm{HCl} \text { appropriate process and outcome indicators } \\
\text { - Inclusion of patient groups, health professional societies, academe, and other } \\
\text { involved stakeholders in the development of accreditation standards }\end{array}$ \\
\hline $\begin{array}{l}\text { Program } \\
\text { Management }\end{array}$ & $\begin{array}{l}\text { - Monitoring of accredited facilities } \\
\text { is inadequate due to shortage of } \\
\text { monitoring staff } \\
\text { - Function only limited to assessment }\end{array}$ & $\begin{array}{l}\text { - Stringent recruitment, retention, and training of surveyors who may be } \\
\text { sourced from DOH Centers for Health and Development } \\
\text { - Surveyors will be more facilitative towards assisting hospitals in developing } \\
\text { and implementing own quality improvement plans } \\
\text { - More frequent visits of at least twice a year, including random site inspection }\end{array}$ \\
\hline $\begin{array}{l}\text { Continuing Quality } \\
\text { Improvement }\end{array}$ & & $\begin{array}{l}\text { - Effective oversight function } \\
\text { - Establishment of a quality improvement committee within the agency }\end{array}$ \\
\hline
\end{tabular}

under DOH Administrative Order 2013-0002 that created the Hospital Accreditation Commission as the National Accrediting Body for Hospitals in the Philippines. To date, PhilHealth is still the primary accreditor of hospitals. ${ }^{19}$

\section{Gaps and challenges in the current accreditation system}

Table 1 shows the various gaps and challenges to the current accreditation system, specifically with PhilHealth as the central agency in the accreditation of health facilities. Based on the literature review by Hinchcliff et al. (2012), taking into account the common program challenges by Zafrifaftar and Aryankhesal (2016), the following domains of an ideal national hospital accreditation system may be considered. It highlights the need for an integrated organizational structure, with strong legal support and managerial competencies of the implementers. ${ }^{6,7}$ It should be encompassing yet detailed enough to specify the operational guidelines. Meanwhile, in attaining and sustaining efficient operations, it is imperative to have adequate financial and human resources to strengthen implementation, monitoring, and evaluation continuously. Also, with the advancement of digital technology, it is apt to invest in infostructure for efficient and timely data sharing and processes. Based on the domains, findings from the literature were classified and further sub-divided as to either gap noted or recommendations deemed fit to address the gaps. ${ }^{11,13,14}$

\section{Health facility accreditation infrastructure}

From the literature review, the UPM HDPH research team proposed a diagram showing the delineation of roles in terms of strategic purchasing with third party accreditors (Figure 2). At present, PhilHealth both purchases and regulates providers of health services through accreditation, while DOH acts as a regulator and provider. By forming an independent accreditation agency, the roles of purchasing, regulation, and provision of health services must be distinct and delineated.

Aside from minimizing duplication of roles, there will be one primary arbiter and champion for each end-goal

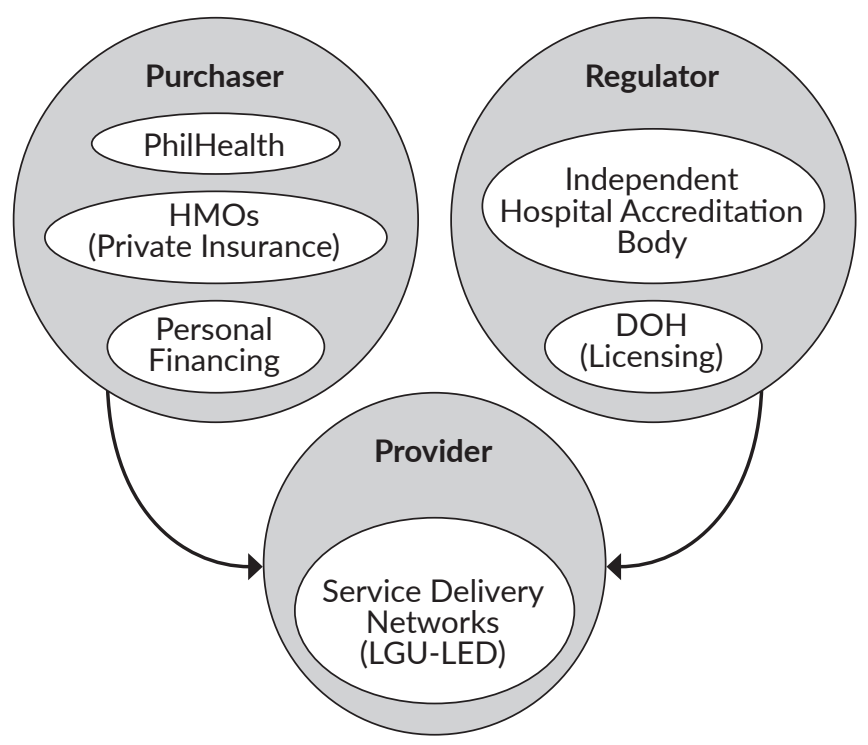

Figure 2. Proposed delineation of roles of key actors in regulation, purchasing, and provision of health services. 


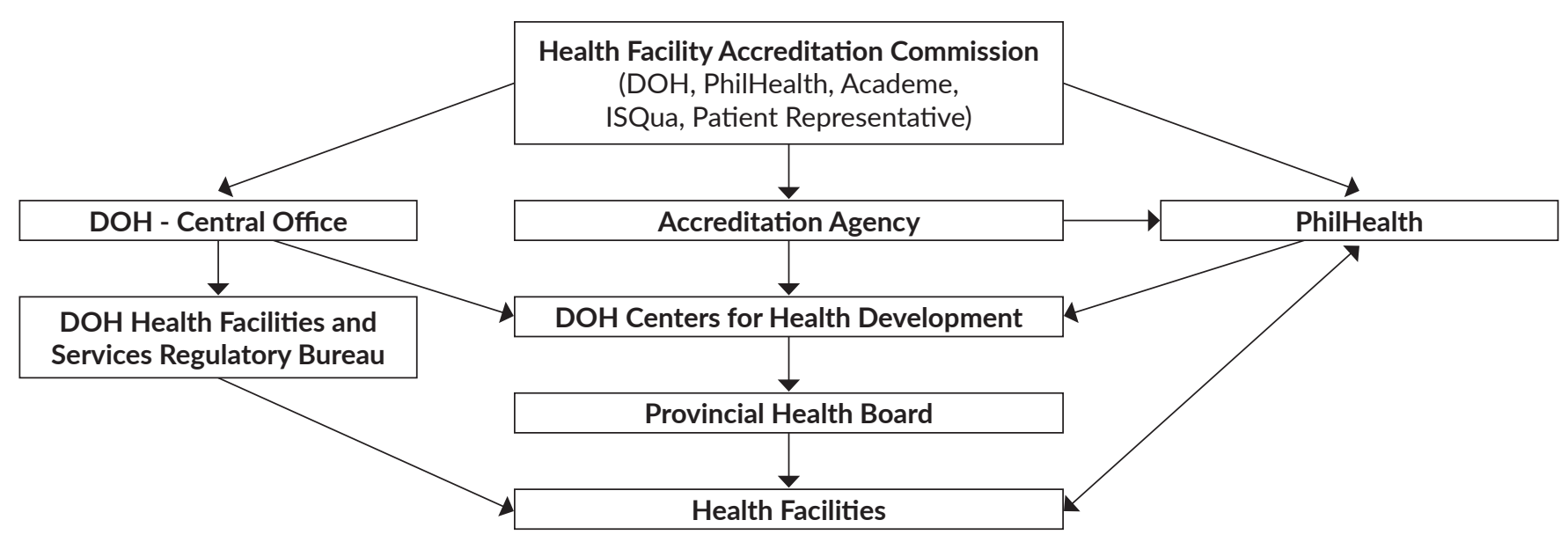

Figure 3. Proposed inter-organizational relationships on accreditation of health facilities.

of a health system-coverage, quality, and financial risk protection, without redundancy of functions. In this set-up, it is envisioned that the Universal Health Care Act will move towards the efficient attainment of all the three goals without sacrificing the quality.

As a driver for improving quality of care, health facility accreditation infrastructure should be institutionalized as a system that addresses the individual attributes of each actor and stakeholder in the accreditation system as well as the relationship between the actors and stakeholders. It must also take into account their competing or conflicting interests. The UPM HPDH research team proposed an inter-relationship between the different actors and stakeholders in the health facility accreditation infrastructure (Figure 3).

A critical component in this infrastructure is the Health Facility Accreditation Commission. It is envisioned to be a quasi-government agency that will work with $\mathrm{DOH}$, accreditation bodies, and PHIC in the aspect of accreditation. Its primary function is to create accreditation standards as well as oversee its implementation throughout the network of health facilities on the ground. The relationship of the commission with its direct clients (health facilities) will be strengthened through the assurance of financial incentives provided by the purchaser, PhilHealth. Likewise, its mandate to serve the people should be strengthened under the quality domains of people-centeredness and integration.

With the current resources available, the third party accrediting body will need support from the $\mathrm{DOH}$ Centers for Health Development. They shall be trained and certified in surveying and technical assistance and provide the results to the accreditation agency. The agency shall inform PhilHealth once a health facility is accredited for immediate facilitation of capitation "global payment" process and contracting of service delivery network, both private and public HCIs.

There are two aspects to the local health system as envisioned in the UHC Act that must be captured in the accreditation infrastructure. One is the health facility on the ground and the provincial-centered health system that these facilities operate in. It is important to highlight these aspects as they play an essential role in the provision of an individualand population-based health services.

When it comes to the accreditation process, two approaches can be taken. One is to focus on health facility accreditation since these are in the front-line of the provision of most individual-based health services. Another option is to have a two-tier approach to accreditation. During the transitory period of implementing the UHC Act, the national coverage of accreditation widens, strengthening the local capacities of province- and city-wide service delivery networks. Upon attaining the facility-based quality standards, accreditation can now shift away from being facility-focused to becoming network focused through PhilHealth contracting. With this, the UPM HDPH research team proposed an inter-organizational relationship for the accrediting service delivery system (Figure 4). In sync with the six years of managerial and financial integration of the new health system, this will give adequate time to make the provincial health system responsive to the needs of its constituents. Thereby, this will holistically assess the performance of the system, including social determinants.

Based on the recommendations outlined, a proposed set of detailed criteria that are fundamental and vital characteristics of the accreditation agency and the health facility accreditation commission is presented and was subjected to discussion. This seeks to operationalize the five domains that characterize a third party accrediting body given as leadership and governance, financing and sustainability, standards development, program management, and continuing quality improvement. Accepted criteria tackled in the discussion were included in the modified criteria listed in the recommendation part of this paper.

\section{Ways forward}

The Universal Health Care Law provides an opportunity to shift the authority to accredit hospitals through a third party, in which some past efforts are noted. With the 


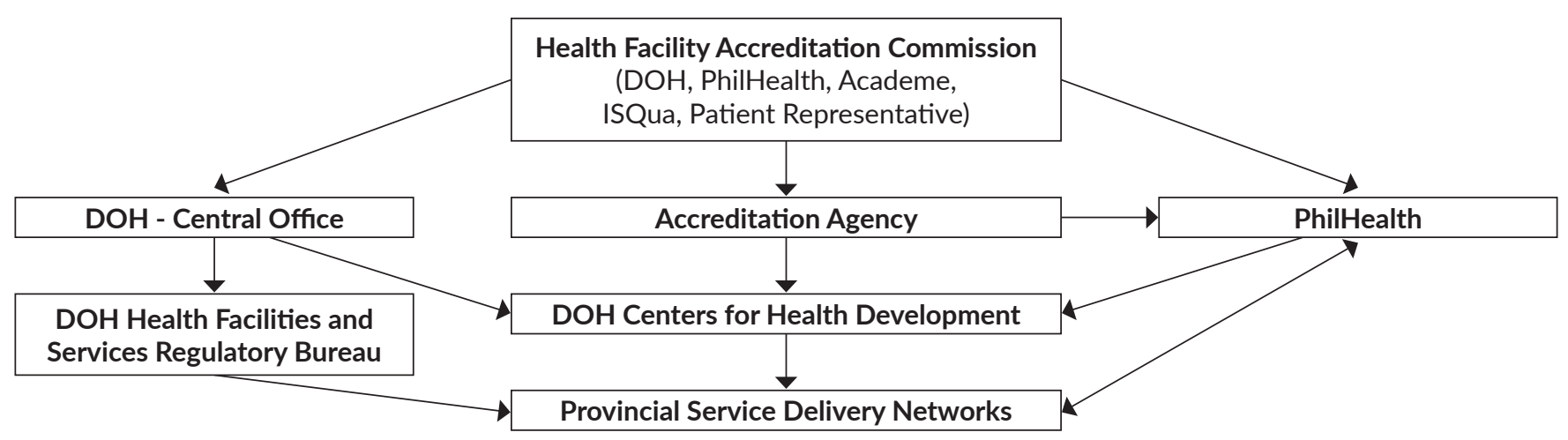

Figure 4. Proposed inter-organizational relationship diagram of accreditation of service delivery networks.

experience of hospitals in quality assurance programs for almost a decade, it is an excellent time to venture to third party accreditation. In order to shift the responsibility of accreditation to a proper independent accreditation body, this must be committed to a formulation of the plan and providing the necessary resources to support it to fruition.

\section{Roundtable discussion}

The UP Manila Health Policy Development Hub, in collaboration with the Department of Health, conducted a roundtable discussion (RTD) on the UHC Act entitled "Moving towards third party accreditation of health facilities" on the 15th of February 2019 at the Hotel Kimberly, Manila. This is the fifth in the series of RTDs that aims to discuss the policy implications of the Universal Health Care Act, specifically on framing the strategies in identifying the criteria and mechanisms of a third party accreditor.

From the initial list of 35 discussants from all major stakeholders of the policy issue, a total of 27 representatives from different sectors took part in the policy roundtable discussion: four from the national government agencies; six from non-government health facility accreditation organizations; six from government and non-government facilities, and each hospital licensing level; three from health professional societies; two from national facility administrator organizations; five representatives from the academe; and one from a patient group. Consent for publication of the RTD proceedings was solicited in the initial correspondence and reiterated during the event. Further, participants were informed that the names of the RTD attendees and specific organizations would be in the Acknowledgments section.

The roundtable discussion aimed to frame the strategies in identifying the criteria and mechanisms of the third party accreditor, taking into account the strengths and weaknesses of the current system and how to address arising fragmentation issues in the implementation. From these, the $\mathrm{DOH}$, as the primary agency, and UPM HPDH, as the research team, had deliberation on the discussion questions that will aid in formulating strategic reforms in health facilities regulation. The following served as a guide in the policy RTD:
1. What is the impact of PhilHealth accreditation, particularly on quality, market, and accountability?

2. What are the good practices of international and local licensing and accreditation?

3. What are the proposed criteria for identifying third party accreditors and their mechanisms?

4. What are the risks and mitigating measures in transitioning from PHIC to an outsourced third party?

The policy brief was presented by a UPM HPDH member, outlining the history up to existing policies of accreditation of health facilities and the current gaps and challenges of the Philippine Health Insurance Corporation (PHIC) as an accreditation system based on available literature. Recommendations were directed in achieving an ideal Philippine accreditation agency that will minimize the overlapping of roles in regulation, purchasing, and provision of health services. To delineate these roles further, the UPM HPDH-proposed inter-organizational relationship on accreditation of health facilities is presented to capture the context and extent of current national health system capabilities. Inputs and recommendations from the participants were solicited to garner more significant agreement on the proposed diagram.

To provide ground experiences in accreditation, key resource speaker from PhilHealth shared the success and challenges of the national health insurance program from the history of standards development, actual surveying of facilities, and impact evaluation. To their end, there was a visible improvement in the number of facilities accredited with more hospitals upgrading based on recent statistics. However, with competing aims, the primary objective would still be the coverage of the population to benefits as it assures them to be protected from financial risks. Internally, human resource for surveying, service availability, data utilization, accreditation cost, and geographic inaccessibility remain to be the critical gaps that establishing third party accreditors aim to mitigate. It is also recommended to have local partners in the provinces to defray the miscellaneous cost of accreditation, such as travel and accommodation expenses of surveyors. 
To further enrich the evidence, key resource speaker from the Philippine Society of Quality (PSQua) presented and contrasted the different accreditation programs being sought locally by facilities.

\section{Policy Analysis}

Transcription of the roundtable discussion and other supporting documents were thematically analyzed with the discussion questions as the sub-themes. Results were combined with the systematic review of literature as inputs to the position statement, consolidating scientific, legal, and expert evidence.

Both the systematic review of literature and policy discussion were utilized as inputs to the policy paper. The consensus statements formulated, under the thematic framework were then circulated to the discussants for further comments and approval. The UP HPDH members reviewed revisions before the final review and approval of the Chancellor.

\section{RESULTS AND DISCUSSION}

Insights and recommendations of the RTD participants were thematically analyzed, guided by the discussion questions.

\section{Impact of PhilHealth accreditation on quality, market and accountability}

A PhilHealth representative shared that more facilities seek to be accredited due to the potentially substantial financial rewards. From the perspective of PhilHealth members, patients prefer to seek health services in PhilHealth-accredited facilities. Visible improvement was noted in the number of facilities accredited with more hospitals upgrading based on recent statistics. However, with competing aims, the primary objective would still be the coverage of the population to benefits as it assures them to be protected from financial risks. Internally, factors such as human resource availability for surveying, service availability, data utilization, accreditation cost, and geographic inaccessibility, remain the critical gaps that PhilHealth hopes to mitigate by establishing a third party accreditor. With a low number of surveyors, it would be a great challenge to examine every complaint against each PhilHealth-accredited hospital. More data is further needed as to the actual client satisfaction surveys, or impact on more encompassing health outcomes of hospitalization rates or re-admission rates. All the raised gaps were generally agreed upon and accepted by the RTD participants. It was then recommended to have local partners in the provinces to defray the miscellaneous cost of accreditation, such as travel and accommodation expenses of surveyors.

Representatives of hospitals agreed that the process towards initial and continuing accreditation promotes behavioral change among individual health workers, leading to a culture of quality improvement and attention to the quality of care, notably patient safety. This leads to individual accountability from the level of the frontline workers to senior management wherein there is an external barometer of success for managers in terms of supporting the whole unit or hospital in surpassing the goals of accreditation.

Similarly, in the patient point of view, perceived improvement of care was noted. However, there is a need to focus on the availability of medicines, noting that there must be more attention in the supply chain management during accreditation.

It is highly suggested that the medical cases catered by hospitals be well managed by systematic referrals of Level 1 and 2 hospitals within the service delivery network (SDN) to help sustain their finances while at the same time, decongesting Level 3 hospitals. Subsequently, decongesting Level 3 hospitals will also help in expanding the market to an international clientele, which has been one of the initial aims of some of these tertiary hospitals for accreditation to international bodies.

\section{Good practices of licensing and accreditation}

Considerations in the manner of conduct of accreditation, the extent of collaboration, and benchmarking with international standards, quality, applicability, and sensitivity of standards, were shed to light. More than the distant intent of improving financial status, accreditation was presented as truly more of improving quality and systems for better health outcomes and experience.

Majority of the participants shared that the standard good practices were the constructive, non-blaming, developmental approach of quality improvement. This ensures ownership of the process that will translate to the individual worker's behavioral change. The internal change management program of each office or unit towards unified development of the whole facility drives positive competition and sharing of good practices within the facility. It must be noted that this approach and mindset matters more to the workers and administration than the promise of having more patients served.

The cycle of accreditation is recommended to be three years in duration, considering the length of time a hospital will be expected to improve. This will also give time for the surveyors to assist actively; and for the facilities to consider accreditation as a means for improvement and not just for the sake of compliance. Further, this will not take too much time for the facility managers in providing services, and other collaborative efforts, especially at the primary care level wherein yearly accreditation measures render around one to three months a year, casting challenges both for the providers and patients. On the other hand, accreditation bodies may lower the cost of the process if the time frame would be longer than the current yearly accreditation model.

There are concerns that the same set of standards will be required for all types of facilities, with free-standing and 
hospital-based dialysis units as examples. It is suggested that the same set of standards will be enforced. However, the number of criteria for a facility to pass shall be appropriate for their classification in terms of service level capacity.

Concerns were raised as well with the different requirements of various accreditation agencies for the same parameter, or inter-inspector variability. This can be addressed by the suggestion to review the standards further to be utilized, to conform with existing laws, such as the Building Code and Fire Code regarding the placement of fire extinguishers, and the requirements from administrative issuances of the Department of Health, Department of Trade and Industry, PhilHealth, and local medical education accreditation bodies.

\section{Proposed criteria in identifying third party accreditors and its mechanisms}

The participants concurred with the various criteria proposed, as referred in Table 1, in identifying third party accreditors and its mechanisms in terms of leadership and governance, financing and sustainability, standards development, program management, and continuing quality improvement.

In leadership and governance, considering the long-term plans that are either stalled or abandoned due to political vagaries and whims, enactment through law or with the implementing rules and regulations of the UHC Act will ensure that the trajectory planned for accreditation be kept on track. The IRR of the UHC Act must enable this accreditor's legal mandate and financial support within its initial years of operation or at least for the first cycle of accreditation. While the majority agreed to a voluntary form of accreditation, a few suggested making it mandatory, especially among government facilities, to keep them genuinely accountable in quality of care.

For standards development, considering the long history of the development of the current Benchbook, it is most prudent to adopt this set of standards. Some have opined that it is best to examine this set to ensure comprehensiveness and inclusion of other domains such as patient and worker experience. Likewise, the details must be checked to evaluate as to the appropriateness of the measurements identified, aligning with outputs and outcomes instead of inputs. Furthermore, the standards set by both the licensing and accrediting bodies must be aligned to minimize the waste of resources in procurement or development. To assess the country as a whole, one even suggested that formative research be conducted wherein the scores of hospitals based on the first Benchbook of Standards be compared to their future scores in the second and currently reviewed version. This shall assess whether quality improvement has been sustained despite the challenges of PhilHealth to provide accreditation due to a low number of surveyors available on the field.

In program management, the capacity levels of the surveyors from the third party body must be adequate and maintained. If found lacking or too few, capacity-building activities must first be conducted. It would be best that the surveyors are trained local experts to understand the local language and context of the health system. Some participants suggested that hospital administrators may provide better managerial and ground experience to the health facilities being surveyed.

On whether a single accreditation body of surveyors or several organizations should be selected, operational criteria that takes into account the commitment capacity of the desired accreditation body should be developed. This can address the current challenges of PhilHealth on having a limited number of surveyors.

In financing the accreditation process, there is a mixed response on who should pay the process of accreditation. Typically, this is shouldered by the hospitals themselves, as it is conducted by private hospitals or corporate government hospitals in pursuing international accreditation. For government hospitals that have limited financing, it is suggested that the government should fully subsidize this fee. It is further suggested that there be a dialogue with local officials, in terms of local government hospitals, to underscore the importance of accreditation and ensure their commitment to improving their facilities.

\section{Risks and mitigating measures in transitioning from PHIC to outsourced third party}

In light of the challenges experienced by the Hospital Accreditation Commission in obtaining necessary powers to implement its supposed mandate, it is hoped that through the UHC Act and accompanying policy instruments, third party accreditation can avoid the same pitfalls.

The usual risks that can be ascertained from the transition are the oversight of the outsourced external third party and the mandate of this third party. As such, stringent parameters of the partnership should be explicitly listed to ensure that the third party accreditor employs limited variability in surveying, while also ensuring that their assessment can still be evident outside the accreditation period. For these, leadership and governance are the key enabling factors. As such, a timeline for this plan should be developed to properly transition this responsibility while also keeping effective oversight over the accrediting organizations.

Concerns were raised on the possibility of advancing the accreditation of an SDN, rather than the single facility. Will this require all health facilities across all levels within the SDN to be accredited first, or should a certain percentage suffice? With the weight of all the resources needed for SDN accreditation, will the accreditation fees be shouldered by the LGU, the national government, or shared among the SDN facilities? Moreover, the accreditation standards for all SDNs should be the same across all regions to ensure quality service. The phased approach of improving the accreditation process and improved quality of individual facilities could coincide with the six-year transition period of a changed 
health system. Therefore, there is an expected significant improvement or maturity of the external evaluation mechanism to overcome those concerns.

Additional concerns arose on the accreditation of individual health providers. Since accreditation requires human and financial resources, it burdens small scale health providers, particularly those in rural areas wherein the travel and accommodation expenses of accreditors will be shouldered. Therein, the suggestion to have strategic accreditation through capacitating DOH Centers for Health Development in accreditation to optimize resources. This runs parallel to the hospital system as a whole, and it proves integral as well considering the wealth of human resources health facilities have to invest in.

\section{CONCLUSION AND RECOMMENDATION}

Moving towards third party accreditation, fostering commitment and compliance to quality service is the core goal. At the level of governance, it renders facilities and health workers more accountable for the services they provide. Further, details are still to be treshed out in the IRR and other issuances to gain more operational perspectives from key implementing actors on the feasibility and timeline of implementation to enable the efficient transition to third party accreditation. What is unanimously agreed upon is that with the long history of PhilHealth in expanding population coverage, the existence and experience of various accreditation bodies, the time is ripe to give premium to quality of care. The standards have already been developed, with the PhilHealth Benchbook, while the various participants assert surveying capacity. The next step is the setting up of mechanisms in the implementing rules and regulations to utilize the available resources towards quality universal health care.

The transitional path towards third party accreditation needs to be defined under a change management approach. Responses from the senior policy-determining executives of the DOH and PhilHealth, and broader representation from all types of facilities must be further gathered to ascertain the feasibility, viability, acceptability, functionality, and sustainability of the proposed mechanisms, particularly on the Health Facility Accreditation Commission. Once a direction is set, strategic and operational plans and policies are to be developed to be able to formalize the arrangements proposed.

A study can be done to craft a more operational checklist of criteria in determining the quantitative and qualitative surveying capacities, and the respective cost, with the distribution of facilities across the geographic expanse of the Philippines. These criteria will be the metric used in determining if there is one or a number of the local third party accreditation bodies capable of performing the functions it will be contracted to perform. It will then be able to guide the level of government support needed in either bringing down the cost of accreditation or widening the access of surveyors.

As the UHC Act explores the formation of health care provider networks and province- and city-wide health systems, conducting discussions, survey, or modeling can ascertain how networks may be captured by various regulatory tools (i.e. licensing, accreditation, self-regulation). Further, this could also determine the extent of sub-national health systems in performing regulatory functions.

Finally, with the limited accessibility of local literature on health facility regulation, research on this topic must be supported to be able to supply the evidence needs towards policy development.

For the criteria in selecting third party accreditor that will ensure attaining its common goals while addressing the existing challenges of PhilHealth in accreditation, the following are recommended based on the literature review and policy RTD.

\section{A. Leadership and Governance}

- The implementing rules and regulations of the Universal Health Care Act must specify the legal mandate and financial support from the government, the Department of Health, or the Philippine Health Insurance Corporation, within its first five years of implementation.

- The mandate of the agency to the Filipinos is to publicly make available its assessment of hospitals as to how well they match the internally developed guidelines covering all dimensions of quality of care, from the availability of services and medicines at the point of care to attend to the patient experience and health workers' satisfaction.

- Accreditation shall be deemed voluntary among the hospitals without any directive mandating all hospitals to undergo accreditation.

- The accreditation body must be composed at its highest decision-making level, or the Executive Board, with one representative each from the Department of Health, PhilHealth, the academe, professional organizations from each cadre of health workers, hospital administrators, hospital owners, standards development officer, accreditation officer, international accreditation society partner, patient or civil society. If this composition is not possible, the composition should be the same composition of the Hospital or Health Facility Accreditation Commission.

- The Executive Board shall decide on the general structure, timeline or cycle of accreditation, levels of accreditation standards, process flow, standards, rating system, and performance levels to be approved for the next cycle of accreditation. The Executive Board shall protect the individual scores of each health facility upon evaluation of the assessor. Likewise, the Executive Board shall assure the integrity of the rating system, or the specific standards set after the phase of assessment has commenced. 


\section{B. Financing and Sustainability}

- Considering the demand for accreditation vis-a-vis accreditation cost to be shouldered by health facilities, it is suggested that the accreditation body be supported financially by the $\mathrm{DOH}$ or PhilHealth during its first cycle of accreditation, of between three to five years. During this time, the accreditation body must be able to project the cost of their whole operations and craft a business plan to be self-sustainable through fees demanded from hospitals for accreditation.

- The accreditation body, through its assessors, must adequately document the cost for hospitals in implementing their plans to meet the standards set. This data will be passed on to PhilHealth to be able to ascertain the incentives provided to accredited hospitals.

- The cost of accreditation could be shouldered by the facility itself as long as it is not prohibitive for the facility. In the case that this will limit the participation of the facility, the government shall step in and subsidize, at the very least, the first accreditation cycle.

\section{Standards Development}

- Standards from all domains of quality, from effectiveness, equity, safety, timeliness, acceptability, and integration of care, must be constructed by the agency through a standards development committee, in coordination with the individual program managers of $\mathrm{DOH}$, and pretested in select hospitals from all levels within various socioeconomic levels.

- The approval of the Executive Board to the standards set by the committee will rest on the process taken in being comprehensive, consultative and context-bound, and not specific to which parameters will be examined, or their respective rating scales.

- Each parameter to be assessed must have an objective assessment tool or document to be used, with objective rating scales for each parameter.

- Outcome and process indicators must be prioritized over structure indicators. Observational, documentary review and on-site surveys shall be the modes of assessment.

- The set of standards must be reviewed after each accreditation cycle without diminishing the level of standards for the succeeding cycle.

- To ensure continuity and uniformity in the development of standards, the current Benchbook of Standards is recommended to be the reference for the next accreditation cycle.

\section{Program Management}

- The external accrediting bodies must first be evaluated on their capacity to deliver the requirements of the National Health Insurance Program. Based on the available market data, PhilHealth shall decide the number and scope of these accrediting bodies.
- The agency must have the available human resource to survey all hospitals to provide a baseline assessment of all hospitals within the first cycle of accreditation, with a time frame no shorter than three years.

- The surveyors should have at least a background in health sciences with the extensive managerial experience of at least five years or training from accrediting bodies.

- The agency must strive to formally certify its surveyors and retain them through fully-sponsored continuing professional development courses.

- The surveyors should not just evaluate or assess but also keep a mindset of Total Quality Management wherein the surveyor should also provide technical assistance and recommendations in their management process of the alignment of all their resources, plans, and budget sought.

- Financial plans of the health facility should be congruent to the Local Investment Plan for Health by the local government unit. Therein, the surveyor must coordinate with the Development Management Officer of the LGU to validate the needs of the facility to deliver quality service. All complaints by the public to hospitals, as received by $\mathrm{DOH}$, PhilHealth, or the hospital itself, shall be evaluated by the surveyor during their visit. The surveyor should check the actions immediately performed, and sustainable plans and development laid down to address and prevent incidents arising from these complaints.

- Assessment will be through announced and unannounced visits, with the final assessment based on the unannounced visit.

\section{E. Continuing Quality Improvement}

- Being an accreditation agency, it must be accredited by a leading internationally recognized association or strive to be accredited within the first cycle of accreditation.

- If accreditation is not a parameter to be required, other measures to assess and ensure that continuing quality improvement for both or either of the accreditation body and PhilHealth should be employed.

- The agency should commit to continuing quality improvement where it is regularly evaluated by legislative oversight agencies, or an external evaluator such as an international $\mathrm{NGO}$, by indicators such as, but not limited to, the number of hospitals assessed, feedback from its clients in terms of their process of surveying, time to complete a single accreditation process, and financial sustainability. It should not be concerned with increasing the number of hospitals accredited so that quality will not be artificially diluted.

\section{Statement of Authorship}

All authors participated in data collection and analysis, and approved the final version submitted. 


\section{Author Disclosure}

All authors declared no conflicts of interest.

\section{Funding Source}

This project was funded by the DOST DOH AHEADHPSR.

\section{REFERENCES}

1. World Health Organization. Everybody's business: strengthening health systems to improve health outcomes: WHO's framework. Geneva, Switzerland: World Health Organization. 2007.

2. Kissick WL. Medicine's dilemmas: Infinite needs versus finite resources. New Haven, Connecticut, USA: Yale University Press. 1994.

3. Faerber AE. Contrasting two frameworks for healthcare strategy. [Internet]. Boston, Massachusetts, USA: Institute for Healthcare Improvement. 2017 [cited 2019 Feb 3]. Available from: http://app. ihi.org/FacultyDocuments/Events/Event-2930/Posterboard-5943/ Document-5657/FaerberStoryBoardTripleAim20170929.pdf.

4. Brubakk K, Vist GE, Bukholm G, Barach P,Tjomsland O. A systematic review of hospital accreditation: the challenges of measuring complex intervention effects. BMC Health Serv Res. 2015 Jul; 15:280. doi: 10.1186/s12913-015-0933-x.

5. Montagu D. Accreditation and other External Quality Assessment Systems for Healthcare. London, United Kingdom: DFID Health Systems Resource Centre. 2003.

6. Hinchcliff R, Greenfield D, Moldovan M, Westbrook J, Pawsey M, Mumford V, Braithwaite J. Narrative synthesis of health service accreditation literature. BMJ Qual Saf. 2012 Dec; 21(12):979-91. doi:10.1136/bmjqs-2012-000852.

7. Zafriraftar M, Aryankhesal A. Challenges of implementation of accreditation standards for health care systems and organizations: a systematic review. J Manag Sci. 2016; 2(3),191-201.

8. Senate Bill 1896. An Act Instituting Universal Health Care for All Filipinos, Prescribing Reforms in the Health Care System, Amending for the Purpose Certain Laws, Appropriating Funds therefore and for Other Purposes. 2018.

9. National Health Facility Registry [Internet]. Manila: Department of Health. [cited 2019 Jan 31]. Available from: nhfr.doh.gov.ph/ Philippine_health_facility_statuslist.PhP

10. List of Accredited Health Facilities [Internet]. Pasig City, Philippines: Philippine Health Insurance Corporation. [cited 2019 Feb 1]. Available from: https://www.philhealth.gov.ph/partners/providers/ institutional/map/
11. Romualdez AG, Dela Rosa J, Flavier JA, Quimbo SA, Hartigan-Go KY, Lagrada LP, David LC. The Philippines health systems review. Geneva: World Health Organization. 2011.

12. Philippine Health Insurance Corporation. Implementing Rules and Regulations of Republic Act 7875 As Amended Otherwise Known As the National Health Insurance Act of 2013. Pasig City, Philippines: The Corporation. 2013.

13. Picazo OF, Ulep VT, Pantig I, Ho B. A critical analysis of purchasing of health services in the Philippines: A case study of PhilHealth. Makati City, Philippines: Philippine Institute for Development Studies. 2015.

14. Tarantino L, Laird K, Ottosson A, et al. Philippines: Governing for quality improvement in the context of UHC [Internet]. Bethesda, Maryland, USA: Health Finance \& Governance Project, Abt Associates Inc. 2016. Available from: https://www.hfgproject.org/ philippines-governing-quality-improvement-context-uhc/

15. Philippine Tripartite Accreditation for Health Facilities, Inc [Internet]. Mandaluyong: Philippine Tripartite Accreditation for Health Facilities, Inc. 2018 [cited 2019 Jan 31]. Available from: https://www. ptahf.org

16. Maramba T. Conference Report: First National Meeting on Quality Assurance in Healthcare in the Philippines. Int J Qual Health Care. 1997; 9(5):381-2.

17. Joson RO. Hospital Accreditation [Internet]. Manila, Philippines: University of the Philippines College of Public Health. c2014. [cited 2019 Jan 28]. 56 slides: color, 25.4 x $19.05 \mathrm{~cm}$. Available from: https:// www.slideshare.net/rjoson/hospital-accreditation-upcphmha202blended-learning-14oct7

18. Department of Health. Designation of the Philippine Council on Accreditation of Health Care Organization as the Authorized Quality Certifying Body for the Quality Standard System of Accredited Medical Clinics/Hospitals. Manila, Philippines: Department of Health; 2000.

19. Estrella RR, Doroteo HE. Introducing the Hospital Accreditation Committee. Escartin IC, Aguirre RG, editors. Manila, Philippines: HEALTHBeat. 2014; (82):14-5.

20. Maramba T, Peralta A. The Philippine Council on Accreditation of Health Care Organizations [Internet]. 2011 [cited 2019 Jun 28]. Available from: https://studylib.net/doc/5209454/hospitalsaccreditation-agency--philippines

21. Diokno B. Should NGO have access to public funds? [Internet]. Quezon City, Philippines: Business World; 2014 [cited 2019 Jan 31]. Available from: http://www.bworldonline.com/content. php? section=Opinion\&title $=$ should - ngos - have-access - to - public funds\&id=85534 